\title{
TU/e emonownen

\section{Analytical calculation of the force between a rectangular coil and a cuboidal permanent magnet}

\section{Citation for published version (APA):}

Rovers, J. M. M., Jansen, J. W., \& Lomonova, E. (2010). Analytical calculation of the force between a rectangular coil and a cuboidal permanent magnet. IEEE Transactions on Magnetics, 46(6), 1656-1659. https://doi.org/10.1109/TMAG.2010.2040589

DOI:

10.1109/TMAG.2010.2040589

Document status and date:

Published: 01/01/2010

\section{Document Version:}

Publisher's PDF, also known as Version of Record (includes final page, issue and volume numbers)

\section{Please check the document version of this publication:}

- A submitted manuscript is the version of the article upon submission and before peer-review. There can be important differences between the submitted version and the official published version of record. People interested in the research are advised to contact the author for the final version of the publication, or visit the $\mathrm{DOI}$ to the publisher's website.

- The final author version and the galley proof are versions of the publication after peer review.

- The final published version features the final layout of the paper including the volume, issue and page numbers.

Link to publication

\section{General rights}

Copyright and moral rights for the publications made accessible in the public portal are retained by the authors and/or other copyright owners and it is a condition of accessing publications that users recognise and abide by the legal requirements associated with these rights.

- Users may download and print one copy of any publication from the public portal for the purpose of private study or research.

- You may not further distribute the material or use it for any profit-making activity or commercial gain

- You may freely distribute the URL identifying the publication in the public portal.

If the publication is distributed under the terms of Article 25fa of the Dutch Copyright Act, indicated by the "Taverne" license above, please follow below link for the End User Agreement:

www.tue.nl/taverne

Take down policy

If you believe that this document breaches copyright please contact us at:

openaccess@tue.nl

providing details and we will investigate your claim. 


\title{
Analytical Calculation of the Force Between a Rectangular Coil and a Cuboidal Permanent Magnet
}

\author{
J. M. M. Rovers, J. W. Jansen, and Elena A. Lomonova \\ Electromechanics and Power Electronics Group, Department of Electrical Engineering, Eindhoven University of Technology, \\ 5600 MB Eindhoven, The Netherlands
}

\begin{abstract}
This paper concerns the analysis of the force between a rectangular coil and a cuboidal permanent magnet. The magnetic flux density distribution due to the permanent magnet is determined using the surface charge method, and an analytical equation is obtained for the Lorentz force on a cuboidal current carrying volume. These analytical results are used to calculate the Lorentz force on a rectangular coil modeled using four current carrying volumes. The calculations are verified both by measurements and numerical integration. These results can be used in the design and real-time control of planar actuators for industrial levitation/positioning platforms or other (ironless) actuators.
\end{abstract}

Index Terms-Coil, Lorentz force, permanent magnet, planar actuator.

\section{INTRODUCTION}

$\mathbf{S}$ INGLE-STAGE magnetically levitated planar actuators [1]-[5] are being researched for use in the lithographic industry (e.g., wafer stages). This requires a positioning accuracy in the nanometer $(\mathrm{nm})$ range. These ironless actuators consist of a stator with coils and a plate with a Halbach array of permanent magnets mounted on it (the translator). To achieve such accuracies, the deformation of the translator plate has to be limited. Therefore, expressions describing the force acting on each PM in the array are needed, since these forces cause the deformation. In previous research, the static forces among the permanent magnets in a Halbach array were determined [6]. A next step is to determine the force resulting from the coils in the stator. For design optimization and real-time implementation, this model has to be accurate and fast.

In previous research on magnetically levitated planar actuators using permanent magnets (i.e., [7]), the force between a cuboidal permanent magnet and a rectangular coil is obtained by numerical integration of the magnetic field of the magnet over the coil volume. A disadvantage of this method is that it is very time-consuming, making it unsuitable for design synthesis. A faster method, which has been used for real-time implementation, makes use of the periodicity of the magnetic field of the array to describe the magnet field using harmonic models [7]. The force acting on the magnet plate is then determined using the Lorentz force equations. Therefore, the model only calculates a force (and torque) vector acting on the magnet plate as a whole and not on individual magnets.

This paper presents analytic solutions to the Lorentz force acting on a current carrying cuboidal volume due to a cuboidal permanent magnet, which are used to calculate the force between a rectangular coil and a permanent magnet. Firstly, the magnetic flux density of the permanent magnet is determined

Manuscript received October 30, 2009; accepted January 04, 2010. Current version published May 19, 2010. Corresponding author: J. M. M. Rovers (e-mail: j.m.m.rovers@tue.nl).

Color versions of one or more of the figures in this paper are available online at http://ieeexplore.ieee.org.

Digital Object Identifier 10.1109/TMAG.2010.2040589

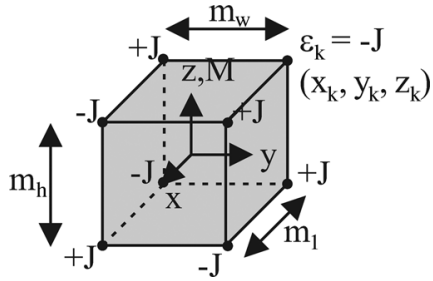

Fig. 1. Permanent magnet modeled using magnetic nodes, magnetization direction indicated by $M$.

using the magnetic surface charge method. Secondly, these expressions are integrated over a cuboidal volume to determine the Lorentz force on this volume and the results are verified by the finite element method (FEM). Thirdly, the expressions are then used to determine the force on a rectangular coil. Lastly, these force calculations are verified both by numerical integration over the coil volume and by measurements.

\section{Modeling of the Permanent Magnet}

The force between a permanent magnet and a coil can be determined by calculating the Lorentz force on the coil due to the magnetic field of the magnet. The force acting on the magnet is then equal to this force but opposite of sign. The flux density of the magnet can be modeled using the magnetic nodes method [8], which is derived from the magnetic surface charge method [9]. These methods assume a relative permeability $\left(\mu_{r}\right)$ of the PM material equal to unity. For a cuboidal permanent magnet as shown in Fig. 1, the magnet can be modeled using eight magnetic nodes at its corners, denoted with the index $k \in\{1, \ldots, 8\}$.

The magnetic flux density $\vec{B}(x, y, z)$ due to the permanent magnet magnetized in the positive $z$-direction as shown in Fig. 1 is given by [8]

$$
\begin{aligned}
& B_{x}(x, y, z)=\frac{B_{r}}{4 \pi} \sum_{k} \log \left(-y_{r}+r\right) \\
& B_{y}(x, y, z)=\frac{B_{r}}{4 \pi} \sum_{k} \log \left(-x_{r}+r\right) \\
& B_{z}(x, y, z)=\frac{B_{r}}{4 \pi} \sum_{k} \tan ^{-1}\left(\frac{x_{r} y_{r}}{z_{r} r}\right)
\end{aligned}
$$




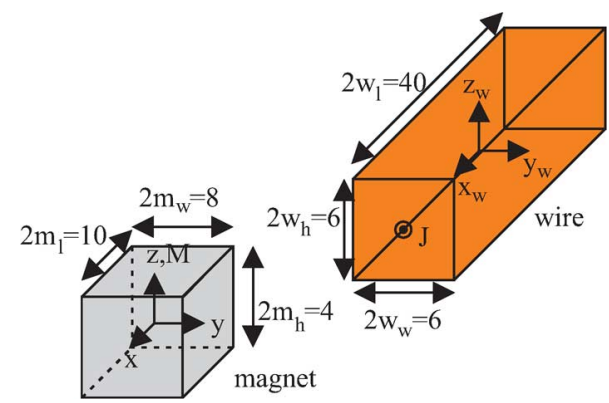

Fig. 2. Permanent magnet and current carrying volume, dimensions in millimeters.

where $B_{r}$ is the remanent flux density of the permanent magnet material (in Tesla), $\left(x_{r}, y_{r}, z_{r}\right)$ is equal to $\left(x-x_{k}, y-y_{k}, z-\right.$ $\left.z_{k}\right)$, and

$$
r=\sqrt{x_{r}^{2}+y_{r}^{2}+z_{r}^{2}}
$$

\section{LORENTZ ForCE ON A CUBOIDAl CURRENT CARRYING VOLUME}

Using the expressions for the magnetic flux density due to a cuboidal permanent magnet, the Lorentz force on a cuboidal current carrying volume can be obtained. The permanent magnet from Fig. 1 together with a wire segment is shown in Fig. 2. Assume the wire segment has a constant and uniform volume current distribution $J$ equal to

$$
\vec{J}_{w}=\frac{I}{4 w_{w} w_{h}} \hat{u}_{x}
$$

where $I$ is the current in the wire segment and $\hat{u}_{x}$ is the unit vector in the $x$-direction.

The Lorentz force equation is

$$
\vec{F}_{w}=\int_{V_{w}} \vec{J}_{w} \times \vec{B} \mathrm{~d} V_{w}
$$

where $V_{w}$ is the volume of the wire segment, $\vec{J}_{w}$ is the current density in the wire segment, and $\vec{B}$ is the external magnetic field. Applying this integral to the current carrying volume and permanent magnet in Fig. 2 results in

$$
\overrightarrow{F_{w}}=\vec{J}_{w} \times \sum_{k} \int_{z_{r}^{\prime}-w_{h}}^{z_{r}^{\prime}+w_{h}} \int_{y_{r}^{\prime}-w_{w}}^{y_{r}^{\prime}+w_{w}} \int_{x_{r}^{\prime}-w_{l}}^{x_{r}^{\prime}+w_{l}} \vec{B}_{k}(x, y, z) \mathrm{d} x \mathrm{~d} y \mathrm{~d} z
$$

where $\vec{B}_{k}(x, y, z)$ is the magnetic flux density due to node $k$ and $\left(x_{r}^{\prime}, y_{r}^{\prime}, z_{r}^{\prime}\right)=\left(x_{w}-x_{k}, y_{w}-y_{k}, z_{w}-z_{k}\right)$. Therefore, the force on the volume is determined by the volumetric integral of the magnetic flux density over the volume of the wire segment. The solutions to the indefinite volumetric integral of the flux density $\vec{B}_{k}(x, y, z)$ are given in

$$
\begin{aligned}
& \iiint B_{x}(x, y, z) \mathrm{d} x \mathrm{~d} y \mathrm{~d} z \\
& \quad=\frac{1}{18}\left(-z^{3}+6 x z r+9 y\left(x^{2}+z^{2}\right) \tan ^{-1}\left(\frac{x}{z}\right)\right.
\end{aligned}
$$

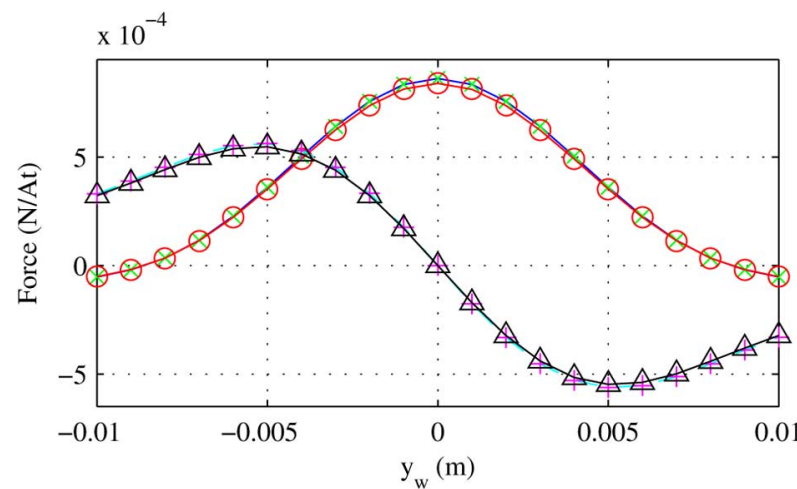

Fig. 3. $F_{y}$ obtained from analytic integral (blue solid line), $F_{y}$ obtained from FEM with $\mu_{r}=1$ (green $\times$ ), $F_{y}$ obtained from FEM with $\mu_{r}=1.05$ (red circle), $F_{z}$ obtained from analytic integral (dashed line), $F_{z}$ obtained from FEM with $\mu_{r}=1$ (magenta + ), $F_{z}$ obtained from FEM with $\mu_{r}=1.05$ (black triangle).

$$
\begin{aligned}
& +3 y^{3}\left(-4 \tan ^{-1}\left(\frac{z}{y}\right)+\tan ^{-1}\left(\frac{x z}{y r}\right)\right) \\
& +x^{3} \log (8)+3 z^{3} \log (x+r) \\
& +9 y\left(z\left(-3 x+z \tan ^{-1}\left(\frac{x y}{z r}\right)\right)\right. \\
& +x\left(2 x \tan ^{-1}\left(\frac{z}{x}\right)+x \tan ^{-1}\left(\frac{y z}{x r}\right)\right. \\
& +2 z \log (-y+r))) \\
& +3 x^{3} \log (z+r) \\
& -3 y^{2}(-4 z+9 x \log (2)+3 z \log (x+r) \\
& +3 x \log (z+r))) \\
& \iiint B_{y}(x, y, z) \mathrm{d} x \mathrm{~d} y \mathrm{~d} z \\
& =\frac{1}{18}\left(-z^{3}+6 y z r+9 x\left(y^{2}+z^{2}\right) \tan ^{-1}\left(\frac{y}{z}\right)\right. \\
& +3 x^{3}\left(-4 \tan ^{-1}\left(\frac{z}{x}\right)+\tan ^{-1}\left(\frac{y z}{x r}\right)\right) \\
& +y^{3} \log (8)+3 z^{3} \log (y+r) \\
& +9 x\left(z\left(-3 y+z \tan ^{-1}\left(\frac{y x}{z r}\right)\right)\right. \\
& +y\left(2 y \tan ^{-1}\left(\frac{z}{y}\right)+y \tan ^{-1}\left(\frac{x z}{y r}\right)\right. \\
& +2 z \log (-x+r))) \\
& +3 y^{3} \log (z+r) \\
& -3 x^{2}(-4 z+9 y \log (2)+3 z \log (y+r) \\
& +3 y \log (z+r))) \\
& \iiint B_{z}(x, y, z) \mathrm{d} x \mathrm{~d} y \mathrm{~d} z \\
& =\frac{1}{6}\left(\left(x^{2}+y^{2}-2 z^{2}\right) r+3 x\left(-y^{2}+z^{2}\right) \tanh ^{-1}\left(\frac{x}{r}\right)\right. \\
& \left.+3 y\left(-x^{2}+z^{2}\right) \tanh ^{-1}\left(\frac{y}{r}\right)+6 x y z \tan ^{-1}\left(\frac{x y}{z r}\right)\right)
\end{aligned}
$$

where $r$ is given by (4).

To verify the analytic solution to the Lorentz integral, the Lorentz force acting on the wire segment was also determined using FEM (Flux 3-D [10]). The force components $F_{y}$ and $F_{z}$ are obtained from (8)-(10) and FEM. The results are shown 


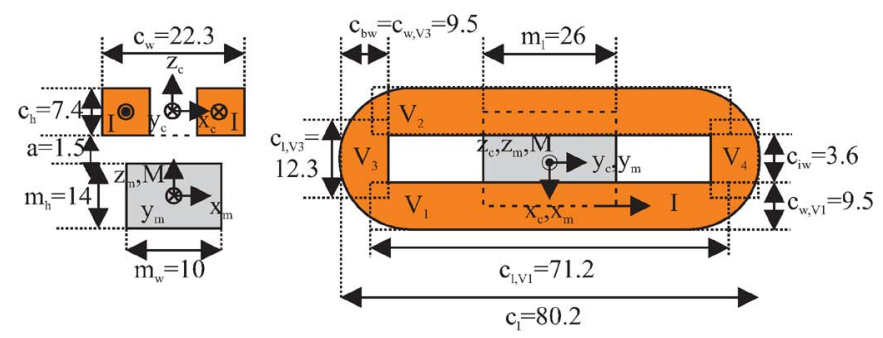

Fig. 4. Cuboidal permanent magnet and a rectangular coil, dimensions in millimeters.

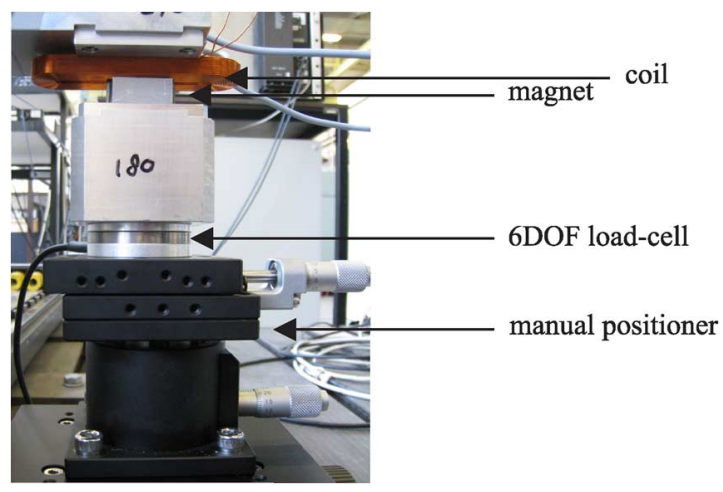

Fig. 5. Measurement setup.

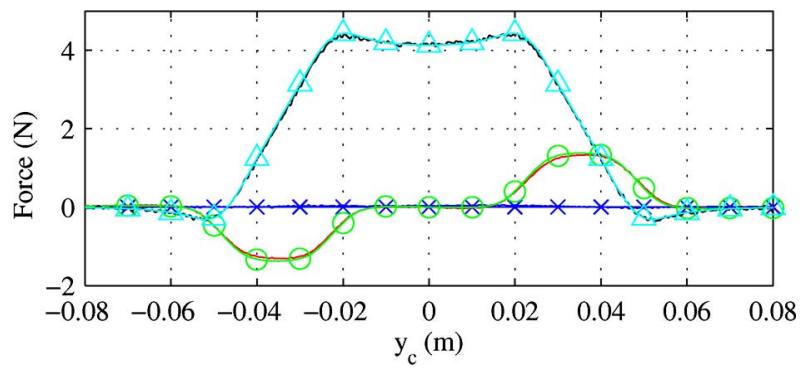

Fig. 6. $F_{x}$ obtained from measurements (blue solid line), $F_{x}$ obtained from analytic integration (blue $\times$ ), $F_{y}$ obtained from measurements (red dashed line), $F_{y}$ obtained from analytic integration (green circle), $F_{z}$ obtained from measurements (black dash-dotted line), $F_{z}$ obtained from analytic integration (cyan triangle).

in Fig. 3 for the wire segment and permanent magnet (with $B_{r}=1 \mathrm{~T}$ ) as shown in Fig. 2, with the dimensions shown in the figure and $x_{w}-x=0, z_{w}-z=7 \mathrm{~mm}$ and variation of $y_{w}$. The force is presented in Newton per ampere-turn (N/At), since the force on the coil scales with the current and the number of turns. The error between results obtained from analytic integration and FEM with $\mu_{r}=1$ is below $0.5 \%$. The $x$-component is not shown since it is zero in this case. In practice, the relative permeability of the magnetic material will have a value greater than unity. To determine the error due to the assumption that $\mu_{r}=1$, the results were also obtained for a typical value of $\mu_{r}=1.05$. The error between results obtained from analytic integration and FEM with $\mu_{r}=1.05$ is below $2.8 \%$.

\section{LORENTZ FORCE ON A RECTANGULAR COIL}

A permanent magnet and a rectangular coil as used in the planar actuator presented in [5] are shown in Fig. 4, with the
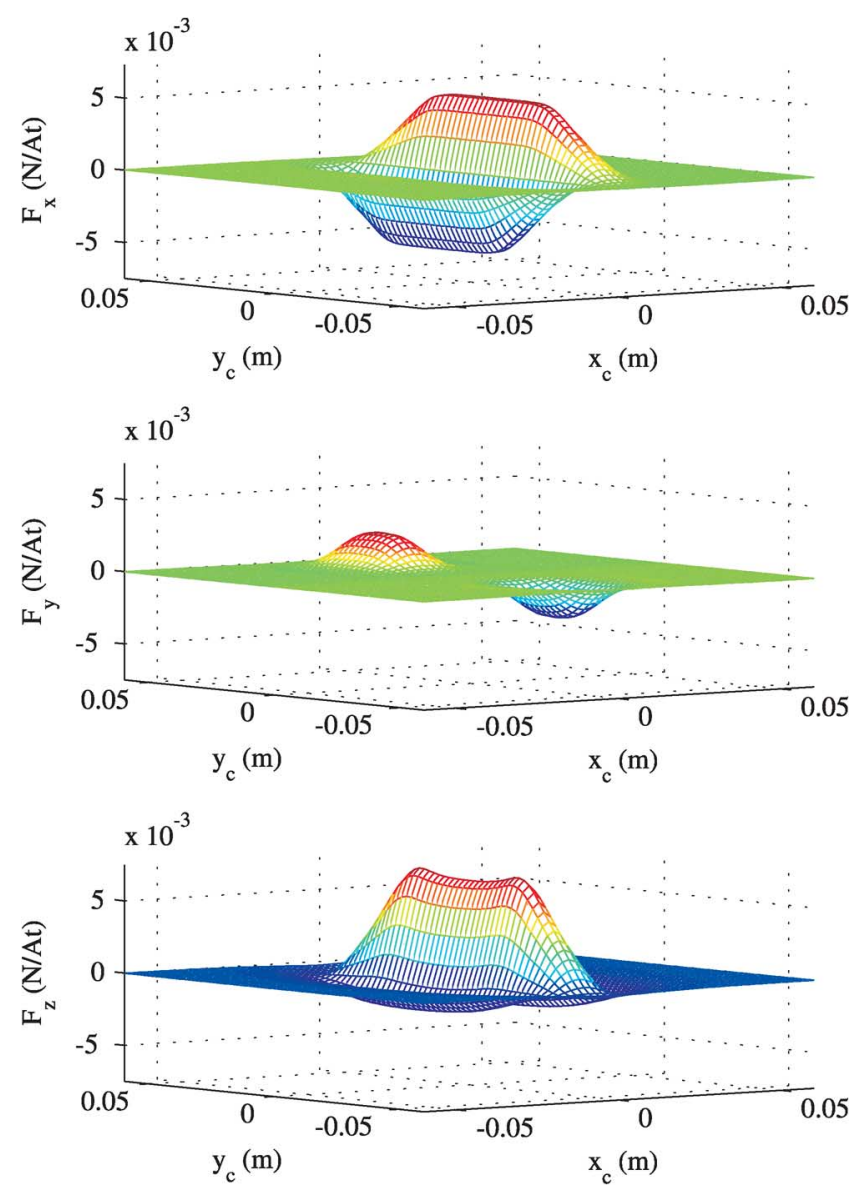

Fig. 7. Force component $\left(F_{x}, F_{y}, F_{z}\right)$ acting on the coil for variation of $\left(x_{c}, y_{c}\right)$ obtained from the analytic integral.

dimensions in millimeters. Since the analytic equations presented in (8)-(10) only offer analytic solutions for the force on a cuboidal volume, the force on the round corners of the coil cannot be determined using these equations. Instead, the rectangular coil will be modeled with the four current carrying cuboidal volumes $V_{1, \ldots, 4}$ as indicated in Fig. 4.

The force acting on each cuboidal volume is calculated using the analytic results of the Lorentz force integral as shown in (8)-(10). The force acting on the rectangular coil is then equal to the sum of the Lorentz force acting on each of the four volumes $V_{1, \ldots, 4}$. These volumes are chosen equal to the dimensions of the straight segments of the coil, with the exception that the lengths of the volumes $c_{l, V 1}$ and $c_{l, V 3}$ are optimized with respect to the results obtained from numeric integration over the coil volume. The dimensions of the four volumes are shown in Fig. 4, where the dimensions of $V_{1}$ and $V_{2}$ and the dimensions of $V_{3}$ and $V_{4}$ are equal.

\section{VERIFICATION}

To verify the analytic method, the force between a permanent magnet (VACODYM 655HR, $B_{r}=1.23 \mathrm{~T}$ and $\mu_{r}=1.05$ ) and a coil (319 windings and a current of 2 A) is measured using a 6DOF load-cell (ATI mini40). The setup depicted in Fig. 5 measures the force on the magnet, which is equal to the force on the coil but opposite of sign. The dimensions of the magnet and the coil are as shown in Fig. 4. Fig. 6 shows the force 

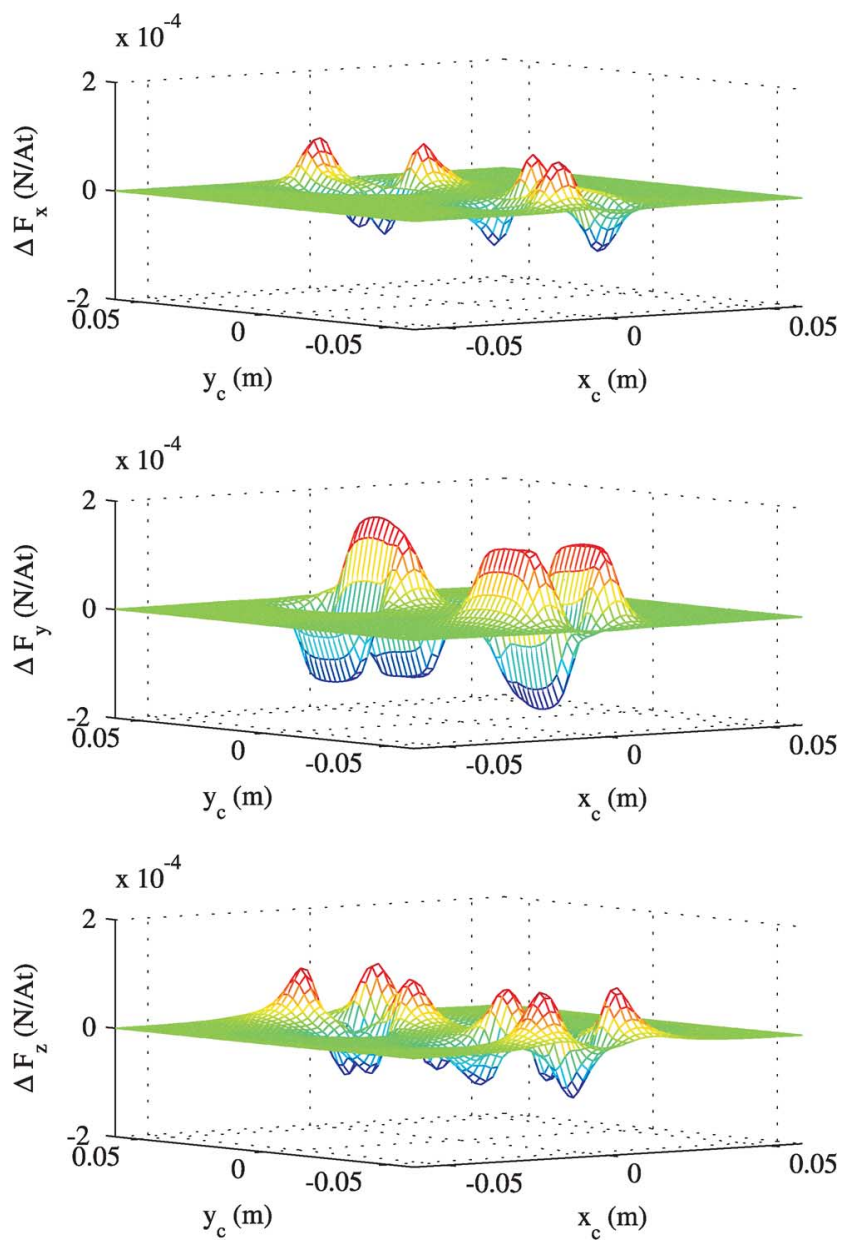

Fig. 8. Difference in results obtained from analytic and numeric integral in force component $\left(F_{x}, F_{y}, F_{z}\right)$.

acting on the coil obtained from the analytic method and from measurements for variation of the coil position $y_{c}$ and $z_{c}-z_{m}=$ $12.35 \mathrm{~mm}, x_{c}-x_{m}=0$. The results show good agreement with a maximum error of approximately $4.5 \%$, which is partly due to the fact that the analytic method assumes $\mu_{r}=1$.

The results obtained from the analytic method are also compared with results from numeric integration over the full coil volume. For variation of the position $\left(x_{c}, y_{c}\right)$, the force components $F_{(x, y, z)}$ (in N/At) acting on the coil as obtained from the analytic models are shown in Fig. 7, with the dimensions of the magnet and the coil as shown in Fig. 4. For the force components
$F_{(x, y, z)}$ the error with respect to values obtained from numerical integration (mesh element size equal to $1 \mathrm{~mm}^{3}$ ) over the coil volume [7] is shown in Fig. 8. This shows that the error is $1.7 \%$ for force component $F_{x}, 6.3 \%$ for $F_{y}$ and $1.4 \%$ for $F_{z}$. In terms of calculation times, the analytic model is over 600 times faster than numerical integration $(0.014 \mathrm{~s}$ for the analytic model against $8.6 \mathrm{~s}$ for numerical integration per grid point).

\section{CONCLUSIONS}

This paper presents analytic equations to calculate the force between a cuboidal permanent magnet and a cuboidal current carrying volume. These equations are used to determined the force between a cuboidal permanent magnet and a rectangular coil. It is verified, both by measurements and numerical integration, that this method is accurate and, compared with numerical integration, the computational load of this analytic method is limited. The method will be used in the design and real-time control of a magnetically levitated planar actuator and is also suitable for the design of other ironless actuators.

\section{REFERENCES}

[1] W. Kim and D. Trumper, "High-precision magnetic levitation stage for photolithography," IEEE Trans. Ind. Appl., vol. 22, pp. 66-77, Apr. 1998.

[2] J. C. Compter, P. C. M. Frissen, J. van Eijk, and P. Frissen, “"Displacement device for use in electric planar motor, has interferometer system for moving carrier over range of centimeters with respect to electrical coil system," Patent WO 2006/075291 A2, 2006.

[3] N. Korenaga, "Alignment apparatus for manufacturing semiconductor device e.g. integrated circuit, has current controller to supply control currents with phase differences to each pair of adjacent ones of stator coils to generate driving force," U.S. Patent 7075 198, 2004.

[4] A. J. Hazelton, M. B. Binnard, and J. Gery, ""Electric motors and positioning devices having moving magnet arrays and six degrees of freedom," U.S. Patent 6208045,2001

[5] J. W. Jansen, C. M. M. van Lierop, E. A. Lomonova, and A. J. A. Vandenput, "Ironless magnetically levitated planar actuator," J. Appl. Phys., vol. 103, no. 7, 2008.

[6] J. M. M. Rovers, J. W. Jansen, E. A. Lomonova, and M. J. C. Ronde, "Calculation of the static forces among the permanent magnets in a halbach array," IEEE Trans. Magn., vol. 45, no. 10, pp. 4372-4375, Oct. 2009.

[7] J. W. Jansen, C. M. M. van Lierop, E. A. Lomonova, and A. J. A. Vandenput, "Modeling of magnetically levitated planar actuators with moving magnets," IEEE Trans. Magn., vol. 43, pp. 15-25, Jan. 2007.

[8] F. Bancel, "Magnetic nodes," J. Appl. Phys, vol. 32, pp. 2155-2161, Sep. 1999.

[9] G. Akoun and J.-P. Yonnet, "3d analytical calculation of the forces exerted between two cuboidal magnets," IEEE Trans. Magn., vol. MAG-20, no. 5, pp. 1962-1964, 1984.

[10] “Flux3D 10.2 User's Guide,” Cedrat Group, Meylan, France, 2008. 